\title{
Bio-inspired approaches to design smart fabrics
}

\author{
Ajay V. Singh ${ }^{\mathrm{a}, \mathrm{b}, *}$, Anisur Rahman ${ }^{\mathrm{c}}$, N.V.G. Sudhir Kumar ${ }^{\mathrm{c}}$, A.S. Aditi ${ }^{\mathrm{d}}$, M. Galluzzi $^{\mathrm{b}}$, S. Bovio $^{\mathrm{b}}$, \\ S. Barozzi ${ }^{\text {e, E. Montani }}{ }^{\text {, }}$ D. Parazzoli ${ }^{\mathrm{f}}$ \\ a European School of Molecular Medicine (SEMM), IFOM-IEO Campus, Via Adamello 16, 20139 Milan, Italy \\ ${ }^{\mathrm{b}}$ Interdisciplinary Centre for Nanostructured Materials and Interfaces (CIMAINA), Department of Physics Via Celoria 16, University of Milan, Milan, Italy \\ ${ }^{\mathrm{c}}$ Instituto di Moda Burgo, Piazza San Babila, 5 - 20122 Milan, Italy \\ d Indira Gandhi National Open University (IGNOU), Regional Centre, 270, MSFC Building Senapati Bapat Road, Pune 411 016, India \\ e Istituto Europeo di Oncologia, IFOM-IEO campus, 20139 Milan, Italy \\ ${ }^{\mathrm{f}}$ Cogentech, IFOM-IEO campus, 20139 Milan, Italy
}

\section{A R T I C L E I N F O}

\section{Article history:}

Available online $\mathrm{xxxx}$

\section{Keywords:}

Biomimetic

Camouflage

Actuation

Bioluminescence

Pulvinus

Stigmata

\begin{abstract}
A B S T R A C T
The nature's intrigue plans to create structures from nano-micro to mesoscale has inspired researchers to design artificial object with novel and extra ordinary properties. Recently, the convergence of biomaterials and polymer advances from nano- to micro-scale with new experimental and computational tools has provided the opportunity to constitute increasingly complex fabrics for the textiles industry. In this regard, learning lessons from efficient natural processes to design smart fabrics, mimicking natural phenomena could revolutionize the textile industry for the design of interactive apparel. Here, we review 10 bio-inspired strategies to imply textile industry, to change the face of fashion and fabrics, based upon current advances in science to enrich diverse areas of textile industry. In each case, we present examples demonstrating nature's design and subsequent parallel advances in biomimetic materials and polymer sciences, combining interdisciplinary engineering principles to mimic nature inspired designs into fabrics. We predict as advances in science of biomimesis continue to unfold and uncover finer details, bioinspired emulations may increasingly give way to benefit in designing smart fabrics.
\end{abstract}

(c) 2011 Elsevier Ltd. All rights reserved.

\section{Introduction}

The rapid growth of research motivation in bioinspired engineering and biomimetics stimulated huge interest of scientist and researchers to apply it for technological innovations. There has been a spirited past of the engineers, architect and scientist, mimicking nature based design to develop splendor and memorable discoveries in the history of mankind [1]. Gaining inspiration from human skeleton and fine structure of bone, bearing enormous body load with greater stability, evoked the design of world famous Eiffel's tower in Paris by Gustavo Eiffel [2]. Anatomist Herman Meyer's cross section of bone revealing porous architect of trabecule, enduring fine balance of tension and compression, inspired Zurich based engineer Cullman to design marvelous Crain which is one of the biggest boon to modern progress in architecture [3]. This bioinspired rich heritage compels fascinating ideas to diverse fields of human life, intended to day by day amelioration of basic needs and comforts. Now, researchers and technologists are concentrating on small scale engineering phenomena, decoding the nature's machinery fold by fold at cellular and molecular level.

* Corresponding author at: European School of Molecular Medicine (SEMM), IFOM-IEO Campus, Via Adamello 16, 20139 Milan, Italy. Tel.: +39 0532 317412, fax: +390250 317482 .

E-mail address: ajayvikram.singh@ifom-ieo-campus.it (A.V. Singh).
By understanding finer details of nature's designs, scientists are bridging the disparity and gap between synthetic and natural arts using scientific methods of investigations and analysis at nanomicroscale. Furthermore, devices emerging from nature's mimicry are looking forward integrating smart sensors, new solar cells and advanced electronics to traditional way of life, defining new era of scientific progress [4].

Smart and intelligent textiles are important developing area in science and technology because of their major commercial viability and public interests. Smart and intelligent textiles/materials can be defined as the materials and structures which can sense and/or respond to the environmental conditions or stimuli [5]. Nature designed biomaterials have structure-functional capabilities that are beyond the reach of manmade materials like silk, leather and wool which are widely used to make clothing [6,7]. If we are successful in harnessing bioinspired approaches to smart fabric design which can perform sensing and actuation, we might be able to create intelligent apparel which is currently considered as science fiction. In biological world, there are many examples of sensing and actuation via mechanical movement or structure-function relationship models, applying a set of external stimuli and responses which provide a robust paradigm to design artificial intelligent materials [8]. The notion of bioinspired, smart material design is intended to perform artificial mechanosensing and actuation 
phenomenon in our daily wearing clothes and apparel for different benefits. Advances in basic science provided colorful insights into fabrics; however, lot more remains to be achieved with the current progress of biopolymers and technologies emerging at micro-nanoscales sciences. Most promising prospect of such fabric engineering approach, uniting nature's machinery with synthetic construct, is that it can be further incorporated into micro-macroscale apparel designs to enhance the structure-functional capability [9].

For example, learning and understanding sensing-actuation mechanism from venous fly trap and touch sensitive Mimosa plant, it is possible to design artificial touch sensitive actuators which can be incorporated into apparels [10]. Light sensing mechanism in algae eyespot inspire designing light sensitive apparel which can be worn as optical protective device filtering harmful light rays from electromagnetic spectrum [11]. Camouflage phenomenon, like in Chameleon, put a natural mechanism to design the dream apparel for the military and defense services to hide or make an entity invisible [12]. Versatile design of human skin sensing pressure and thermal stimuli are other landmark bio-inspired phenomena to be incorporated in apparel, enabling them sense like "artificial skin" [10]. Recently, the science and technology at micro-nanoscale, such as micro- and nano-electronics has given us impetus to learn and understand water repellent lotus phenomenon, to design artificial water and dust repellent nano-fabrics, mimicking lotus leaf surface [13]. Cloths emulating spider man's capabilities are no more distant thought. Modern tools empower us to design gecko like adhesive features which will enable us not to escape from bullet injuries but also equip to stick on the solid rock and metal walls [14]. In addition, design of nano-electronic-fabrics (e-fabrics) is not far from our reach when we will be able to incorporate all fancy e-gadgets such as cellular phone, i-pod and portable computer like chip features in our daily apparel [15]. Moreover, these design features will fulfill the appetite of mankind to draw natural leather features of animals and plants for which animals have been killed up to the edge of extinctions. Thus, it will help in saving our natural wild life, plants and animals. In this review, we are borrowing concept and designs from nature inspired details to incorporate in fabrics and apparel, riding on the wave of modern sciences and technologies. Indeed, such concepts will revolutionize the textile industry to reiterate new saga in the history of fabric design. The references provided herewith this review are by no means exhaustive, but serve as a starting point for more detailed studies.

\section{Design of anti-dust, water repellent fabrics: lotus leaf microfabrication model}

Ever clean, anti-dust and water repellent properties of glassy lotus (Nelumbo nucifera) leaf arise from its surface micro-topography, without detergent or spending energy. The plant's cuticle unlike other plant is made up of soluble lipids, embedded in a polyester matrix - wax but the extreme degree of its water repellency arises due to special surface topography which provides superhydrophobicity. Microtopography of the lotus leaf exhibit extensive folding (i.e. papillose epidermal cells) and epicuticular wax crystals jutting out from the plant's surface, resulting in a roughened micro-texture [16]. This microarchitecture tend to reduce adhesive force on water droplets as trapped air in the interstitial spaces of the roughened surface result in a reduced liquid-to-solid contact area, making the lotus leaf surface less prone to adhere water and dust particles (Fig. 1).

Polar water molecules tend to coalesce due to increase cohesive forces among them which lead to spherulation of water drops. Reduction in surface area between water-leaf's microtopography over 95\% (passing breeze) causes the water drops to roll off due to gravity, taking the attached dirt particles with them, and cleaning the leaf surface forever. Modern nanoscience and microfabrication techniques are equipped with tolls and techniques to design such features artificially and incorporate it into fabrics to give water and dust repellent apparel [13].

Learning microtopography from aforementioned lotus effect, researchers have created superhydrophobic poly-lactic acid (PLA) fabrics via UV-photografting of hydrophobic silica particles functionalized with vinyl surface group over silica microstructure as shown in Fig. 1. Advantage of the technique utilized herewith is that such models can be successfully integrated not only in

\section{Schematic to fabric with coated silica Particles, functionalized with \\ Vinyl group those make \\ fabric hydrophobic}

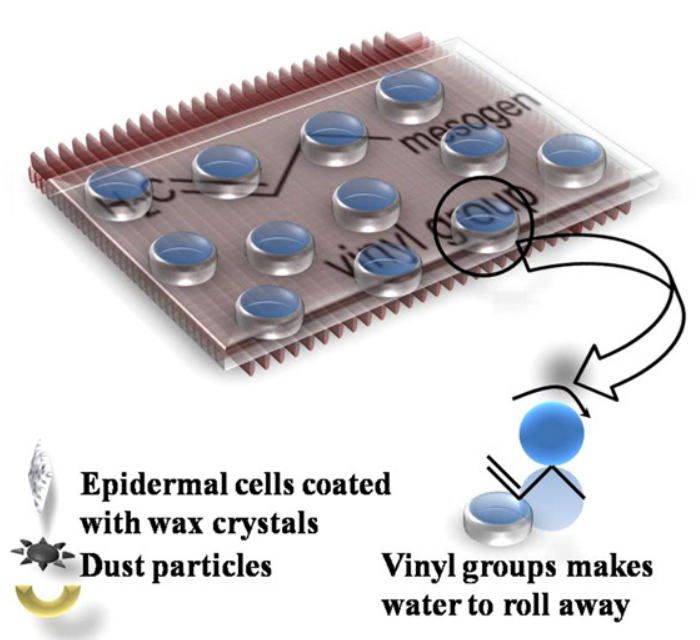

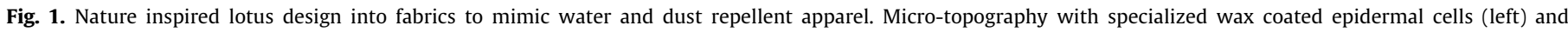
conventional design mimicking the anti-lotus effect into smart fabric design. 
PLA but also in fabrics, exhibiting a robust method to design water and dust repellent fabrics [17].

\section{Design of light sensitive apparel: algae eyespot-stigmata design}

Light reception and reflectance in plants provides a novel strategy of photosensing at higher level of sophistication to perform shape recognition, stereo and locomotion, responding to changing directions of lights. A simple unicellular alga cell of Chlamydomonas sps. swims forward as well as backward in response to harmful UV radiation, equipped with a flagellate engine called eyespot or stigmata [18].

Inspired by such natural phenomenon, scientists have created photosensitive optical polymers fibers that can be successfully integrated into textiles. Strategy involves making gratings of polymethylmethacrylate (PMMA) cladding and methyl methacrylate copolymer cores (Fig. 2). This methacrylate core-clad is further doped with benzyl methacrylate co-monomer (with strong UV absorption) containing a photo-initiator benzophenone and trans-4-stilbenemethanol (a molecule which undergoes photoisomerization). This hierarchical assembly exhibits stigmata like sensitivity and can be applied to block UV rays from light, protecting skin and soft tissues [19].

\section{Touch sensitive apparel design: touch-me-not (Mimosa sps.) pulvinus design}

Touch sensitive plant Mimosa pudica shows human muscle's actin-myosin like quick sensing and actuation with its leaf-moving muscle, so-called pulvinus which performs touch sensitive hydraulic actuation. Pulvini are swollen part at the base of Mimosa leaf stalks or petioles which act as autonomous organ, housing mechano- and photoreceptors that enables leave to move in response to external stimuli [20]. Anatomically, all pulvini comprise thickwalled, water-conducting vascular tissue, surrounded by thinwalled motor cells. These specialized cells undergo visible swelling and shrinking, actuated by changes in turgor pressure and rapid growth expansion across leaf epidermis involving ion transport as shown in Fig. 3. One striking similarity exhibited by pulvinus microstructure with animal joints is their motor cells which bear analogous flexion (flexor cells on upper site) and extension movements (extensor cells on lower site). Increase in turgor pressure and volume caused by the uptake of $\mathrm{K}^{+}$ions in the extensor cells lead to full extension of leaf while flexor undergoes a measurable shortening upon stimulation via evoked action potential, triggered by touch or sudden darkness. This exhibits one of the remarkable weathering phenomena in plant tissue when touched and exemplifies the fastest plant movements [21].

Mimosa pulvinus mediated touch sensitive actuation put forth an enormous opportunity to design fabrics which shrink and de-shrink in response to external stimuli such as touch, sound and/or light. In fashion industry, this would represent a dream opportunity to come true when models walking on ramp will show folding-unfolding modes of smart fabrics with novel sensing capacity. Adopting functional mimesis to the Mimosa leave pulvinus, researchers have designed haptic fabrics by knitted smart materials with touch therapy features. Such wearable fabrics equipped with actuators and sensors perform artificial massaging and aromatizing functions while walking [22]. Most important, such fabrics could provide a sympathetic side of apparel design

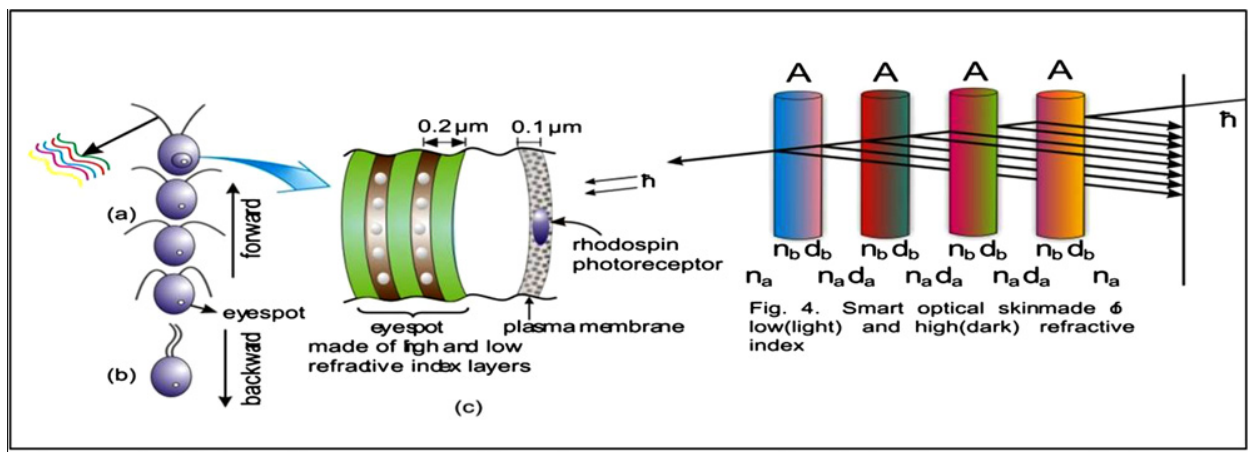

\section{Stigmata in Chlamydomonas sps. Showing upward and back froth movement in flagellar assembly in response to UV-light mediated by their photoreceptor sensing and actuation mechanism}

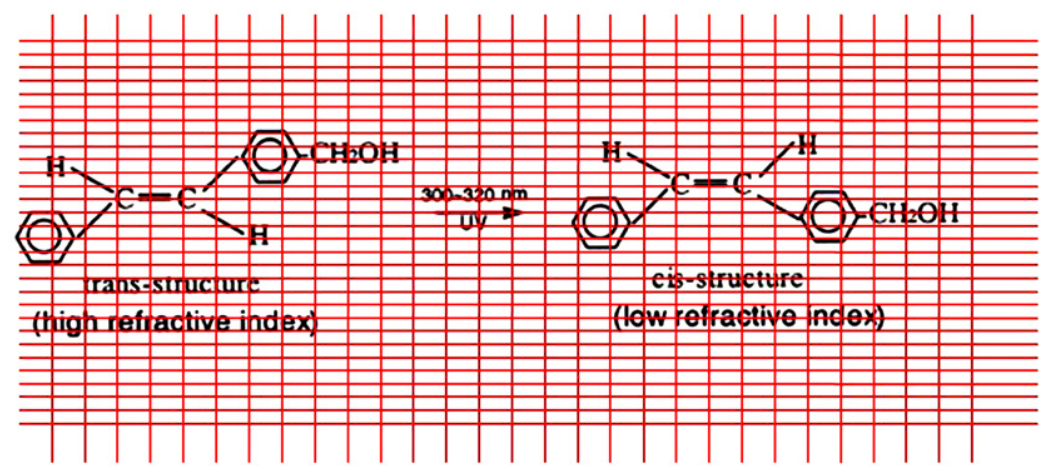

\section{Integrating chemistry in fabrics makes interacting UV sensitive apparel based On doped phtotinitiator which under isomerization upon UV absorption.}

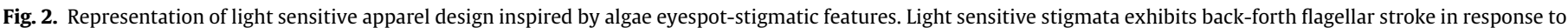

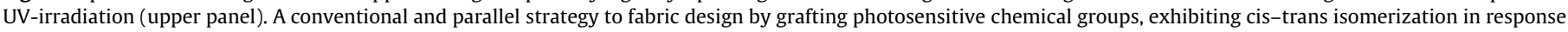
to UV-light (lower panel). 


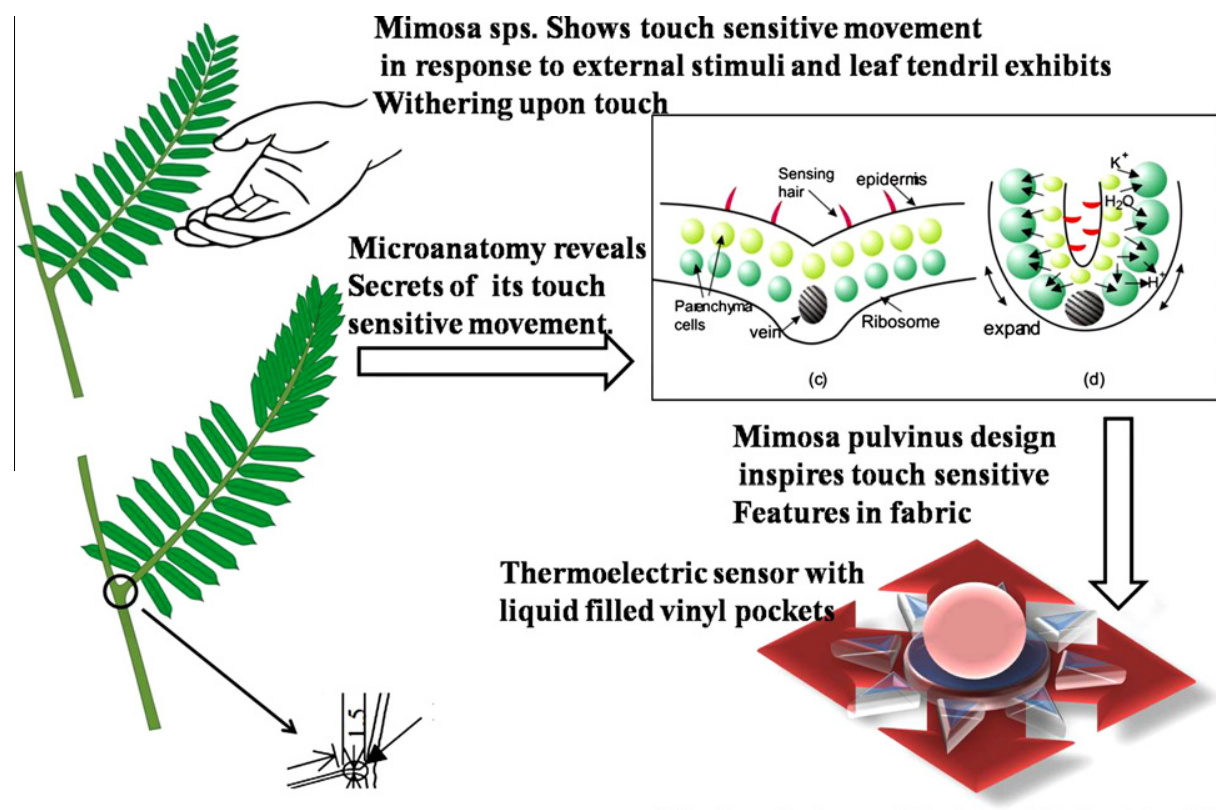

At the base of the petiole, Pulvinus actuation is the real

Vinyl pockets are filled in with liquid, which source of leaf withering diffuses around the massaging wooden ball through thermoelectric sensors

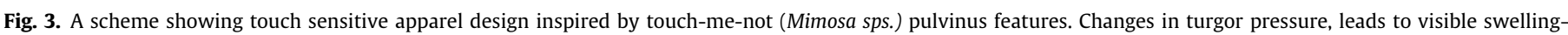

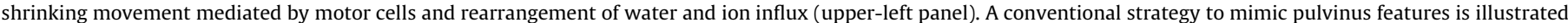
in lower panel, exhibiting touch sensitive fabric model.

by attending, understanding and responding to another person's emotional expressions, a fundamental requisite of elderly person, spending lone time in hospitals [23]. A display of such fabric design plan is depicted in Fig. 3.

\section{Pine cone inspired hygroscopic movements to design smart breathing fabrics}

The scales of seed-bearing pine (Pinus radiate) cones move in response to changes in relative humidity. This hygroscopic movement is motivated by a structural-functional mechanism at the base of each seed petal or scale (that houses the developing seed) of the pine cone. When dries, it automatically opens up by moving away the scales gape, facilitating release of the cone's seed [24]. Whereas when it is kept in moist (damp) environment, scales close up (Fig. 4). Microscopic anatomy of Monterey sps. cones reveal two types of scale growing from the main body of the cone-the ovuliferous scale and the bract scale. The larger ovuliferous scales bear microscopic sclerenchymatous (cellulose) fibers on upper and lower surface $(8-12 \mathrm{~mm}$ in diameter, $150-200 \mathrm{~mm}$ long). It respond to changes in relative humidity by opening-closing cone aperture when season changes [25]. In addition, orientation of cellulose microfibrils between two layers of scales and their expansion in response to relative humidity further controls the vital bending of the scales, facilitating opening-closing of the cone aperture for seed dispersal [26].

This natural phenomenon inspired the researchers to mimic the pine cone for designing humid sensitive adaptive cloth, delivering relief from the discomfort caused by moisture in clothing microclimate as experienced in urban environments. The fabric design utilizes two layers: one of thin spikes of wool, another waterabsorbent material which opens up when gets wet by the wearer's sweat, like ovuliferous scale in pine (Fig. 4). When the layer dries out, the spikes automatically close up again. An underneath second layer protects the wearer from the rain and this smart fabric works like breathing cloth, taking dry air in while closing the fabric pores and moist air out while opening [27]. Such fabric could adapt to changing temperatures by opening up when warm and shutting tight when cold, just like a pinecone's bract.

\section{Chameleon skin, fish scale derived material design for camouflage apparel: cryptic coloration}

The phenomenon of camouflage in certain fishes and amphibian occurs due to excellent iridescent lateral stripes or spots which change their color from blue-violet under low light to green, orange and/or red under increased light intensities [28]. The reflected iridescent colors are produced by the constructive interference of light from the stacks of thin alternating transparent layers with different refractive indexes. The fish and Chameleon skin has a specialized layer of cells under their transparent outer skin which are filled with chromatophores or alternating layers of iridophores, guanine crystals. In the Chameleon, a layer of dark melanin housed in melanophores is situated in deeper skin layers and contains reflective iridophores, which exhibits phenomenal camouflage (Fig. 5).

These specialized cells filled with pigment granules are located in cytoplasm, and their beauty of the color changing capabilities lies in the efficient dispersion of the pigment granules as per changing intensity of incident light [29]. High illumination causes the photoreceptor chromatophores to open up sodium channels and resulting accumulation of hydrated $\mathrm{Na}^{+}$ion increases the thickness of the cytoplasmic layers. Reverse phenomenon takes place in low light illumination and variation in the wavelength of the reflected light stimulates the pigment cells to rapidly relocate their pigments and color of the skin. It gives them inherent ability to adjust their body color and remain indiscernible from the surrounding environment, i.e. camouflage [30].

Inspired by this nature's cryptic phenomenon, scientists have designed choleric liquid crystals (CLCs) to alter the visible color of an object to create the thermal and visual camouflage in fabrics. 


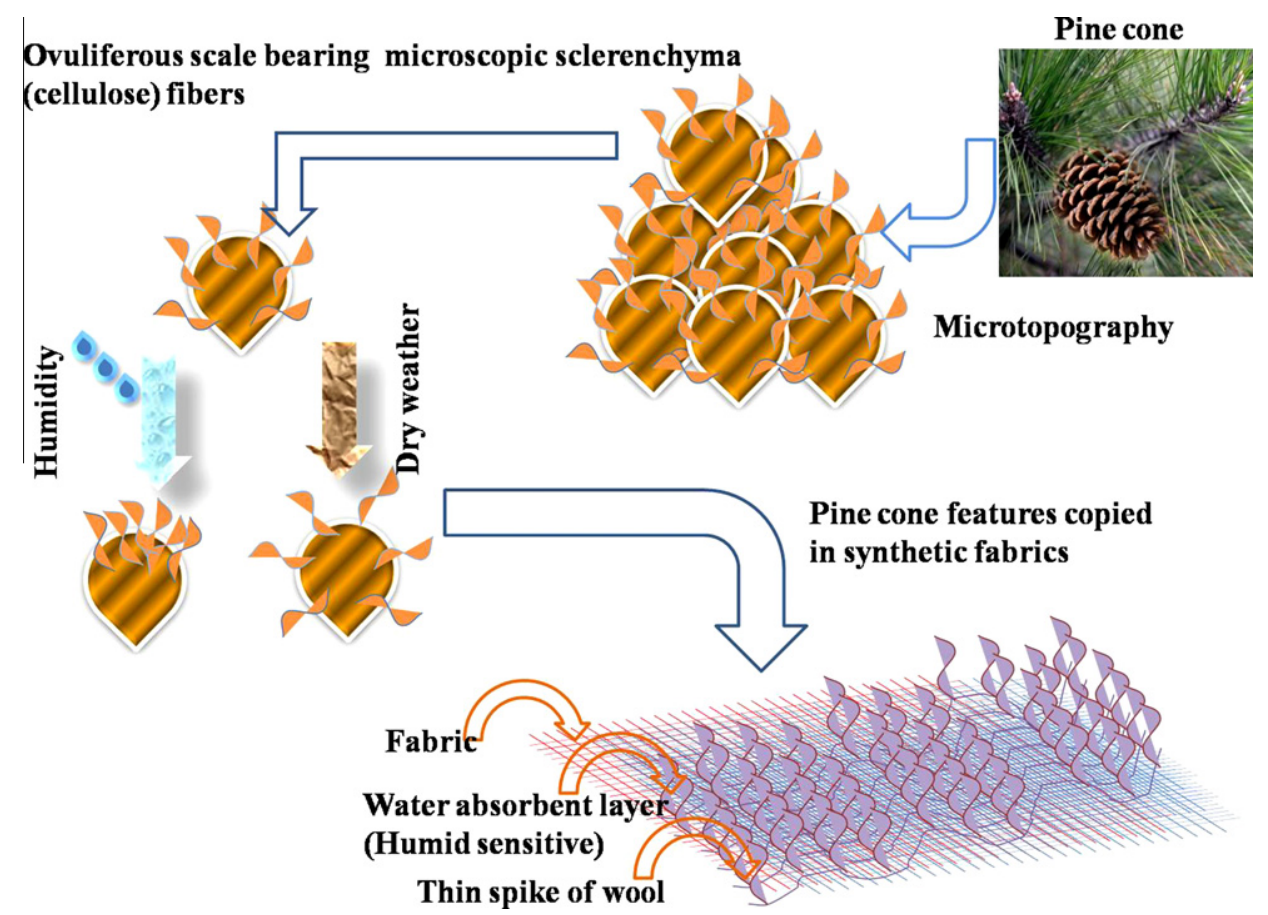

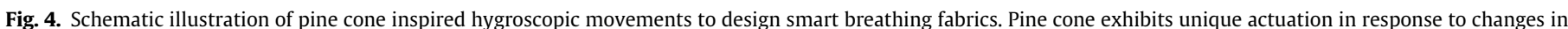

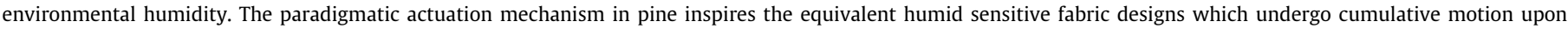

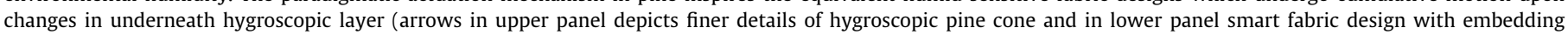
different layers of humid sensitive smart fibers).
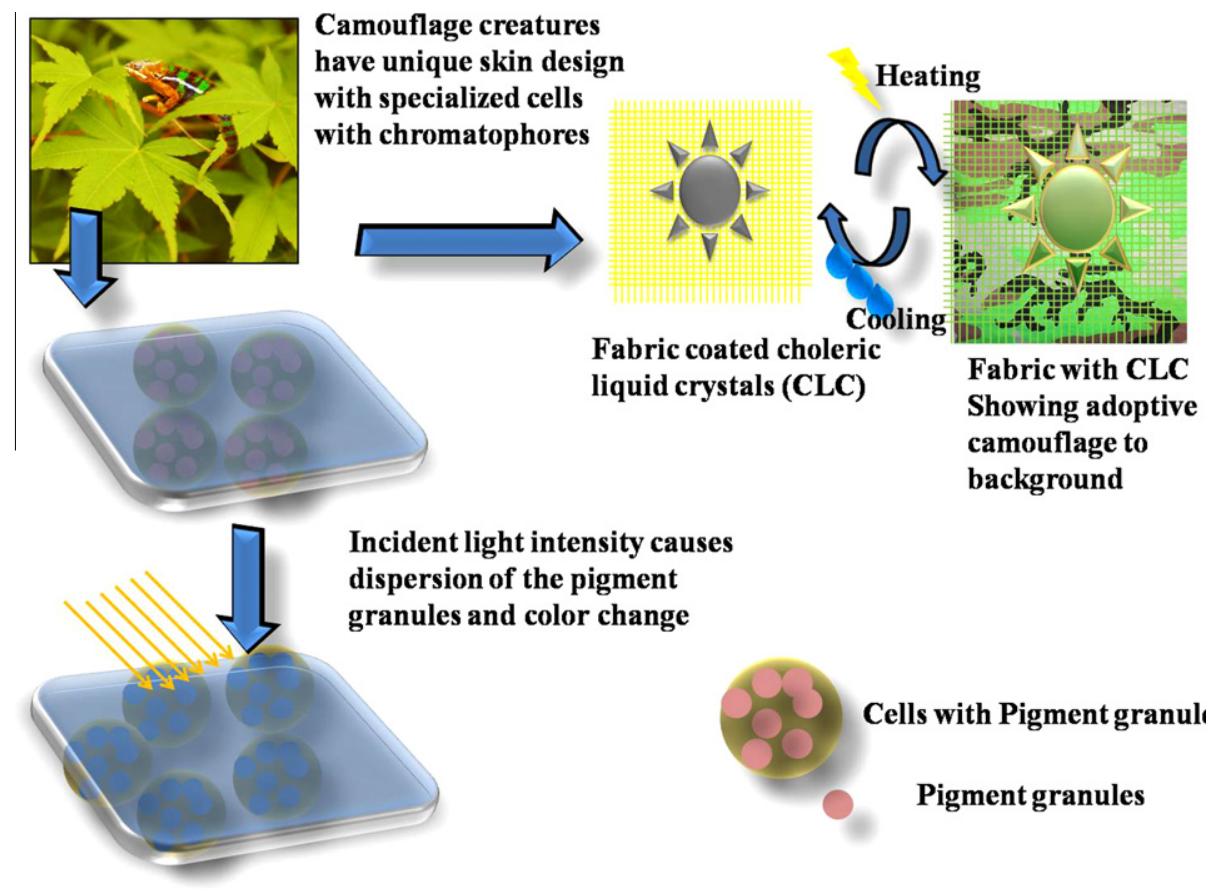

Incident light intensity causes

dispersion of the pigment

ranules and color change

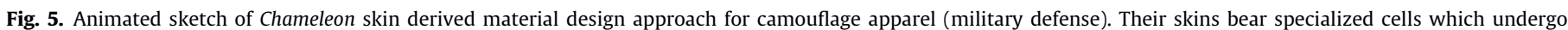

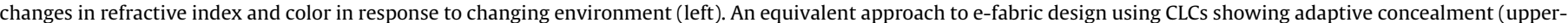
right).

The color of CLCs can be changed with temperature sensitive thermocouples [31]. The heating-cooling ability of thermocouples can be used to adjust the color of the liquid crystals to match the object's background color, providing camouflage or adaptive concealment as schematically depicted in Fig. 5. Moreover, nat- ure-inspired camouflage in animals has stimulated optical camouflage research in fabric design to develop and impregnate the phased optical array (OPA) like holographic designs in three dimensional hologram of background scenery, on an object to be concealed [32]. 


\section{Self healing fabric design inspired by nature's healing mechanism in mammalian tissue}

Nature's self healing ability has inspired new ideas and mechanism which are of fundamental interests for the engineers in designing self healing fabric [33]. Healing process in mammals is much complex and involves hemostasis (arrest of bleeding), inflammation (recruiting immune cells to clear of any microbial population and cell debris), proliferation (growth of new tissue), and remodeling (retaining tissue shape like before injury) as shown in Fig. 6. All these events take place spontaneously and autonomously in ordered phases, triggered by injury processes at wound site albeit healing process is time consuming. Moreover, in mammals, the intrinsic mechanism of healing evolved around the chemical reactions of a series of active enzyme cascades and their inactive precursors, known as clotting factors [34]. An important aspect of the mammalian healing is the rapid hemostatic response to arrest the bleeding and thereafter actual tissue and skin healing starts which is a more lengthy process. In mimicking bio-inspired self-healing program, a reasonably rapid response is required to restore the degree of structural integrity or prevent crack propagation while applying it to fabric design. In addition, mimicking such enormously complex and lengthy process for smart fabric design has limitations due to the lack of replenishment of the engineering components in the system designed for self-healing fabrics [35].

Nonetheless, nature's healing machinery has inspired chemists/ engineers to propose new ideas and mechanisms with different healing concepts which offer the ability to restore mechanical performance of materials via fusion of the failed surfaces. Using biological bleeding approach to healing, White et al. has created the microcapsules reinforced with hollow fibers, polymer composites. This lightweight material exhibits high stiffness and superior elastic strength over the conventional materials [36]. Microencapsulation of self-healing components involves the use of a monomer, dicyclopentadiene (DCPD), stored in urea-formaldehyde microcapsules dispersed within a polymer matrix. When microcapsules are ruptured by a progressing crack, monomer is drawn along the fissure where it comes in contact with a dispersed particulate catalyst (ruthenium based 'Grubbs' catalyst), initiating polymerization, thus repair the crack (Fig. 6). Release of active components has clearly shown the restoration of the lost mechanical properties arising from the macroscale crack within a polymer matrix. Moreover, results confirmed that the dispersion of microcapsules within composite laminate material was not detrimental to stiffness of the parent architecture [37]. A notable advantage of the microencapsulation self-healing approach is the ease with which it can be incorporated into a bulk polymer material which could be a potential self healing reinforcement agent for the future fabrics.

In another landmark approach to design smart fabrics, the selfhealing rubber like material has been designed which acts as molecular glue and seals the lost end when two broken pieces are brought together. This thermosensitive polymer material has been made by simple supramolecular chemistry of fatty acids and urea, provides an exciting opportunity to be incorporated into fabrics [38].

\section{Learning from firefly glow: designing e-circuited luminescent fabrics}

Light production (glow) in fireflies arises on account of an enzyme catalyzed (luciferase) bio-chemical reaction called bioluminescence. This process occurs in specialized light-emitting organs, usually on a firefly's lower abdomen (Fig. 7). The enzyme luciferase acts on luciferin, in the presence of magnesium ions $\left(\mathrm{Mg}^{2+}\right)$, adenosene triphosphate (ATP) and oxygen to produce light [39]. This chemical process provides inciting motivation to design glowing clothes in dark that would add valuable assets to fabrics and textile industry. In this age of nano-innovation, researchers are able to produce at large scale the light-emitting devices with fabric printed circuit boards (PCBs) and successfully connect them with wearable display format using socket buttons [40]. Thus, enabling firefly glow in fancy dresses, utilizing electronic textile

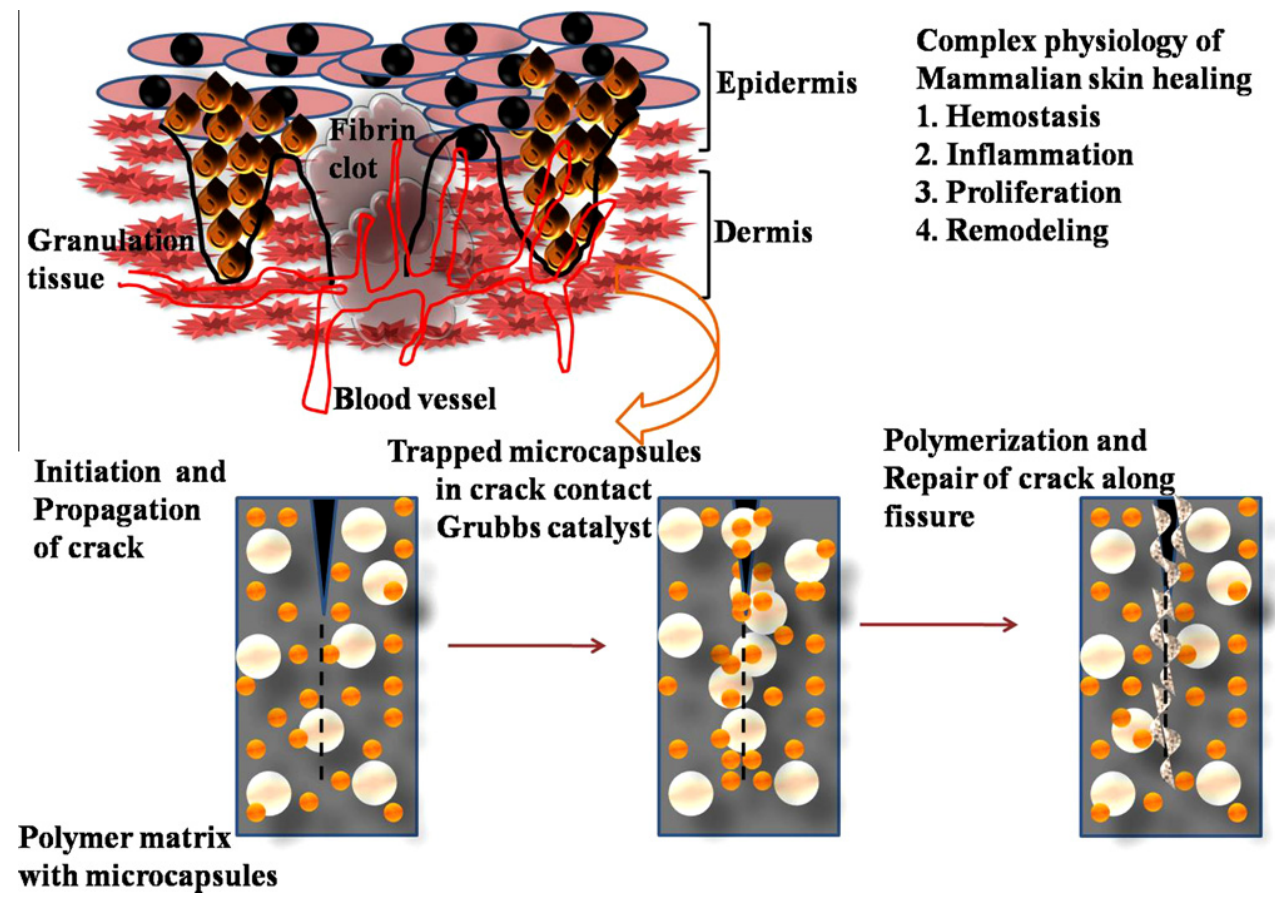

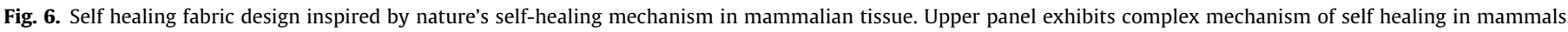
Lower panel gives a physic-chemical route as self healing fabric design (arrow indicates and an equivalent design feature for fabrics). 


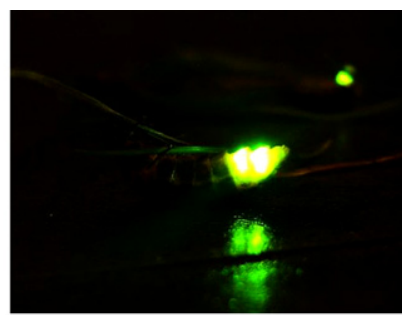

Firefly glow in night exhibits one of nature's unique Bio-chemical reactions showing twinkling attractions For designers and researchers.

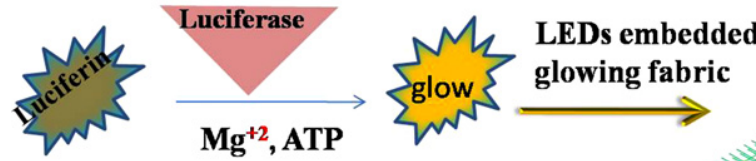

A prototype of bioluminescence in firefly inspired Fabric design for smart "glowing" apparel

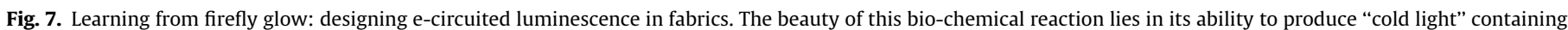
zero UV or IR rays. The glow phenomenon inspires to design luminescent fabrics by coupling light-emitting diodes (LEDs) mimicking firefly bioluminescent.

engineering (e-fabric) design. In one such innovation, researchers have designed two layers of conductive organza: one acting as power and other as ground plane. Small light-emitting sources (LESs) are attached randomly to the fabric with Velcro brushes at their ends. When both ends of the LESs are brushed against the power and ground planes, while the person wearing the dress walks, the circuit is complete and the dress lit up [41]. In addition, inspired by natural glow, Philips has created Lumalive fabrics with flexible arrays of colored light-emitting diodes (LEDs) fully integrated into the fabric, without compromising the softness or flexibility of the cloth (Fig. 7). The most interesting aspect of Lumalive technology is that it can carry dynamic messages, graphics or multicolored surfaces on wearable fabrics.

Thus, we are not far away from a future where personalized clothes will be used as source of advertisement and promotion of commercial product [42].

\section{Spider silk inspired anti-tear fabric design: apparel with Spiderman's suit mechano-elasticity}

Spider (family Theridiidae) creates its web extruding proteinaceous spider silk from its spinnerets to trap the insects for feeding [43]. Proteinaceous spider silk is one of the natural silk exhibiting unique material properties with unparalleled combinations of stiffness, strength, extensibility and toughness, exploiting hierarchical structures as exhibited in Fig. 8. The silk's strength and flexibility come from the nanoscale crystalline reinforcement in which stiff nanometer-size crystallites are embedded and dispersed in softer protein matrices [44]. This is unique, the way these tiny crystals are oriented towards and strongly adhere to the stretchy protein which forms their surrounding polymeric matrix [45].

Inspired by spider silk micro-nanocrystallite design, engineers are now able to model in the lab materials which have strength and stretchability similar to spider silk [46]. The synthetic nanoreinforced structure emulating natural spider silk provides an opportunity to synthesize and conjugate polymer nanocomposites in future fabrics which will potentially rival the most advanced materials in nature. Using a new solvent-exchange approach that is amenable with current textile industry [47], engineers reinforce the hard microdomains of commercial polyurethane elastomer (a polymer or plastic consists of long chains composed of small repeating molecular units) with tiny clay discs (about $1 \mathrm{~nm}$, or a billionth of a meter thick and $25 \mathrm{~nm}$ in diameter) (Fig. 8). The interesting aspect of this reinforced molecular nanocomposite is that it can be easily tuned to make fibers similar to stretchy compounds such as nylon or Lycra for traditional textile industry.

\section{Shark skin inspired low hydrodynamic surface drag: high efficiency swimsuits design with antibacterial effect}

Aquatic animals are gifted with nature's versatile design and surface features to move swiftly in water at the cost of low energy expenditure. In aquatic environment, water drag is the major hurdle for movement. Most shark species (superorder Selachimorpha) move in water with high efficiency and maintain buoyancy due to special ingenious anti-drag design of their skin which reduces drag by $5-10 \%$ [48]. Scanning electron microscope studies have revealed the tooth-like scales of shark skin, called dermal denticles (little skin teeth or riblets) which are ribbed with longitudinal grooves (aligned parallel to the direction of local flow of water). It produces vertical vortices or spirals of water, keeping the water closer to the shark's body, thus, reducing the surface drag (Fig. 9).

This fine microstructure varies from one location to another depending upon the body part participating in hydrodynamic balance while swimming. The V-shaped scales approximately $200-500 \mathrm{~mm}$ in height and regularly spaced $(100-300 \mathrm{~mm})$, are present over most of the shark's body [49]. Moreover, this microscale longitudinal ridges influence the fluid flow in the transverse direction by limiting the degree of momentum transfer and the ratio of scale height to tip-to-tip spacing has critical role in reducing the longitudinal and transverse drags. Another remarkable feature associated with this unique shark scale feature is its microtopography that acts as antibacterial fouling surfaces and microorganisms find it inhospitable to attach on such grooved surface [50].

Inspired by natural design, scientists are adding technological improvements to swimming suits by designing antimicrobial fabrics without the chemical treatments. Especially in Olympic swimming competitions, $1 / 100$ th of a second can make the difference between winning and losing the event. Now such important sport events are heading towards technological support since swimmers are using swimming suit designed on the hydrodynamics principles of a shark's skin. These tightly fitting suits, covering rather a large area of the body are made up of fabrics which are 


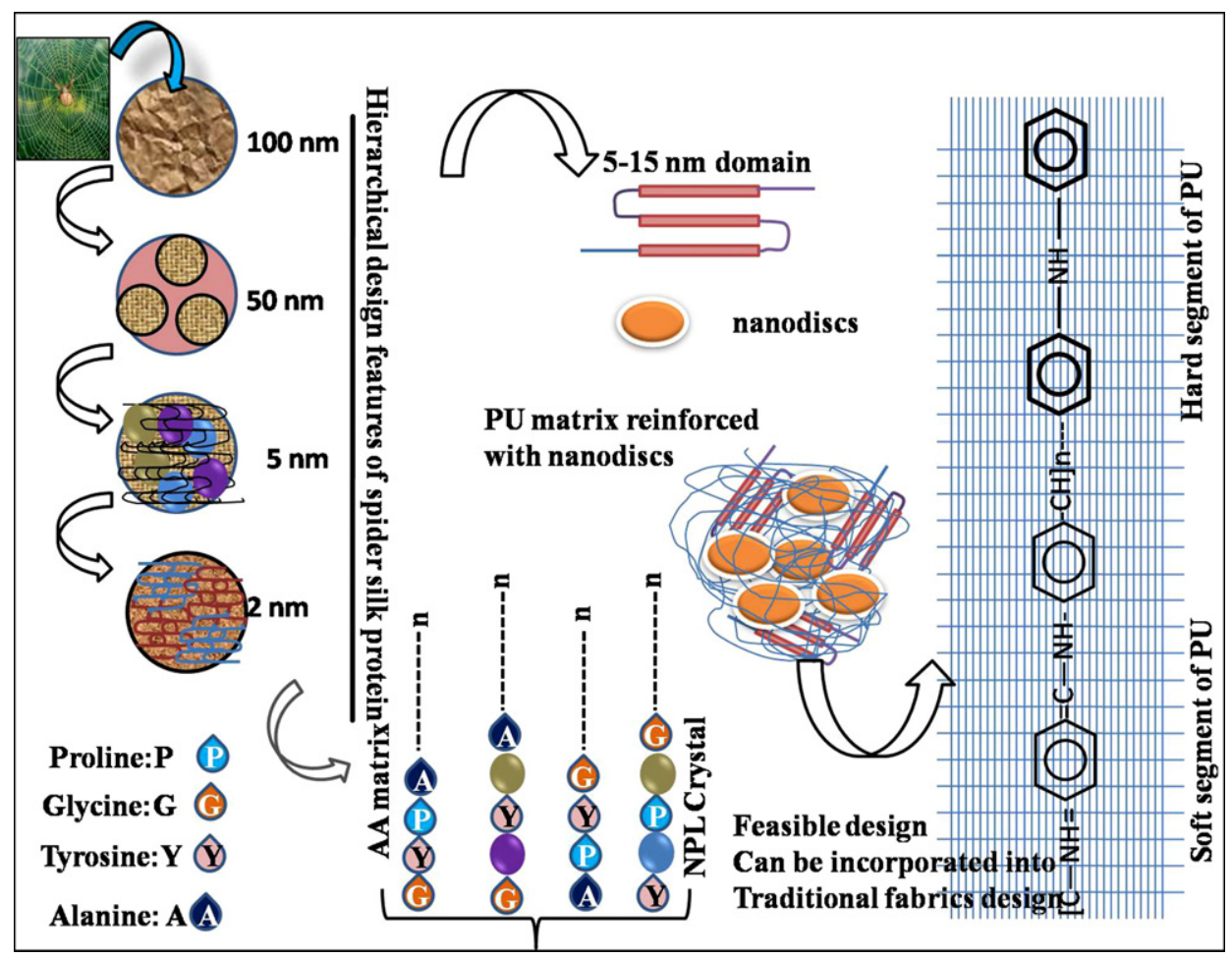

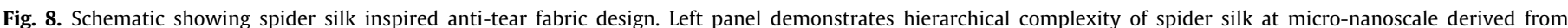

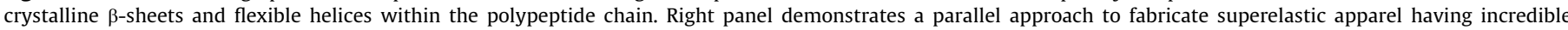

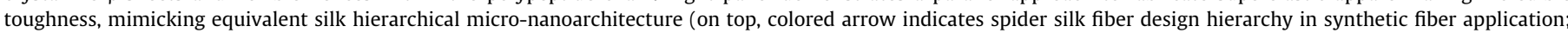

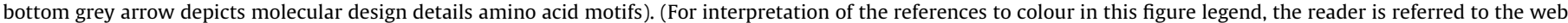
version of this article.)

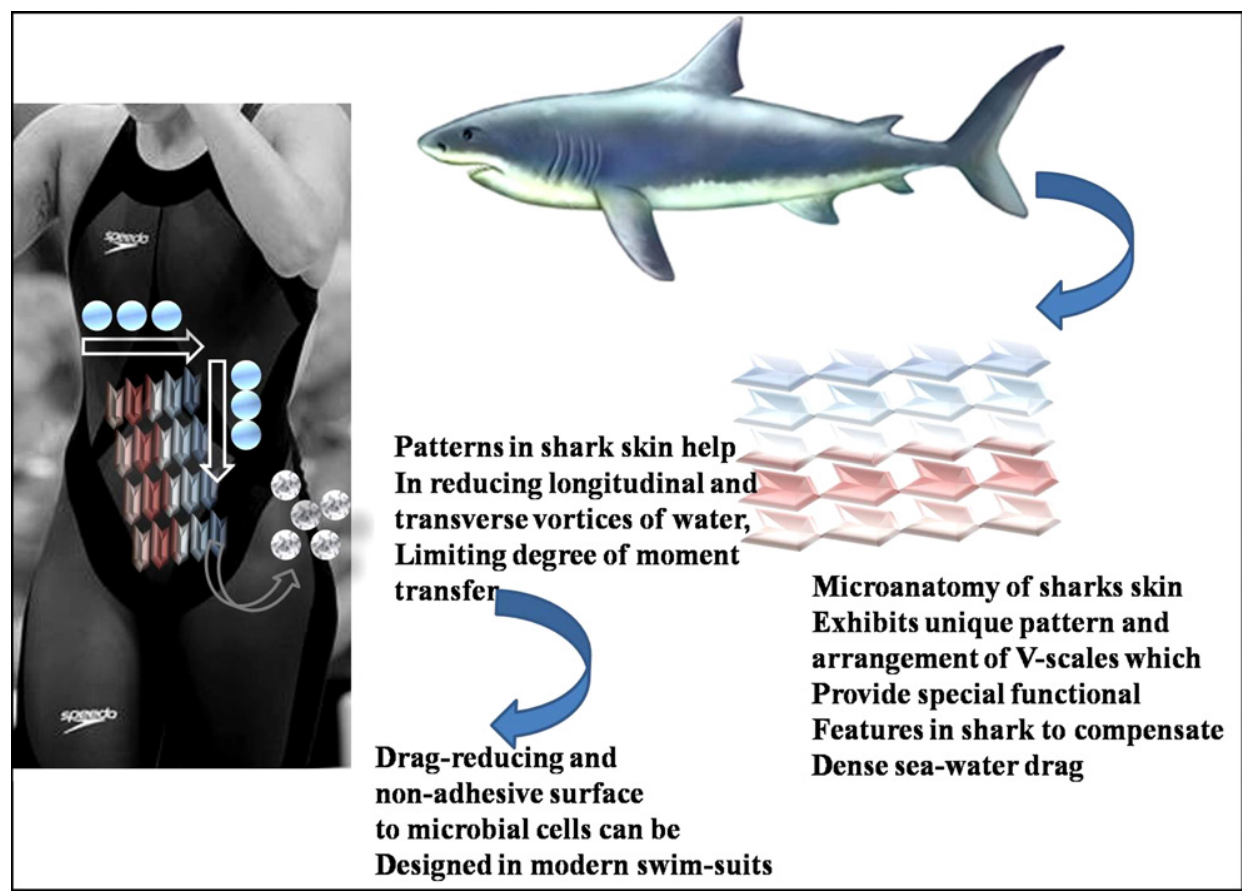

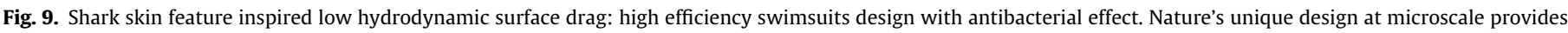
enormous reduction in surface drag of water close to the body (Riblet effect). Arrows show anti-microbial features mimicking shark skin micro-topography.

designed to mimic the properties of a shark's skin by superimposing vertical resin stripes [51]. This phenomenon is known as the Riblet effect (Fig. 9). Swimsuits made with the new fibers and weaving techniques mimicking shark scales microfeatures, are produced to cling tightly to the swimmer's body. It may give the wearer a 6-m equivalent head start in swimming competition by dampening turbulence in the immediate layer of water, next to the skin [52]. 
Moreover, engineer and designers have scientific proof that the shark's body is covered in dermal denticles which will not trap bacteria, because they cannot adhere to the skin and get wash away [53]. It inspired researcher to design equivalent microtextured fabric called Sharklet to explore the "surface topography" which repels the germ (Fig. 9). The most interesting aspect of this antimicrobial fabric design is that it does not utilize any chemical to kill bacteria and only prevents the adhesion. Thus, there will be negligible chances of microbial resistance unlike multidrugresistant in Staphylococcus aureus (MRSA) where microbes develop resistance against chemical therapeutics $[53,54]$.

\section{Mammal skin inspired thermo- and pressure sensitive fabric design}

Mammalian skin is one of the most versatile nature's creations which provide protection (epidermis) and regulate thermomechanical and emotional (pain) environment of the body surface via multiple sensing capabilities. In the skin, sensors are distributed in form of arrays, estimated to have 50 receptors per $100 \mathrm{~mm}^{2}$ over body surface giving fine spatial resolution and high sensitivity [55].

Skin harbors unique mechanoreceptors such as Meissner's corpuscle (tactile corpuscle for light touch) and Pacinian corpuscle

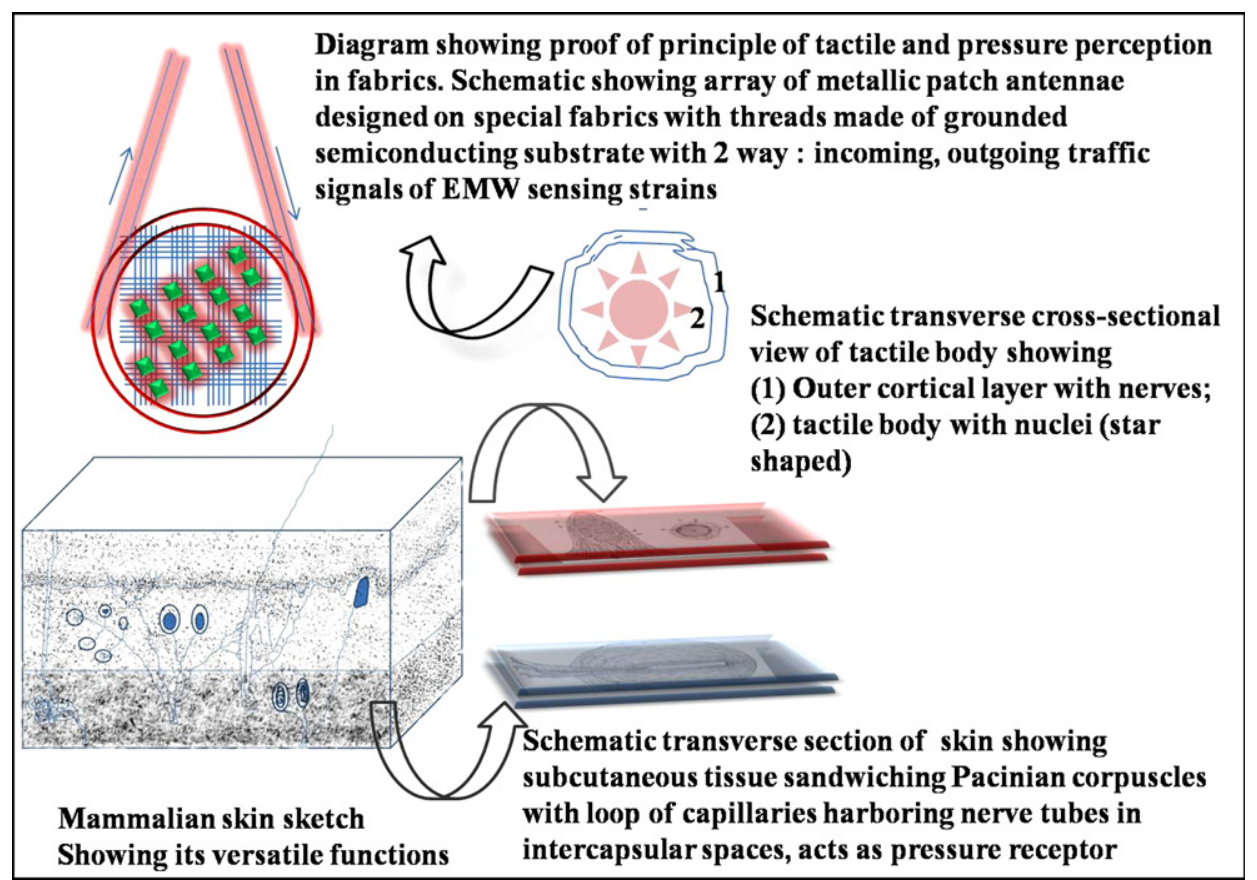

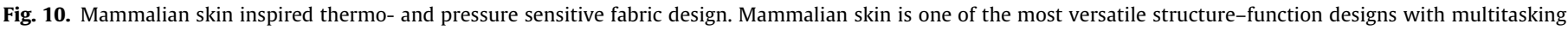

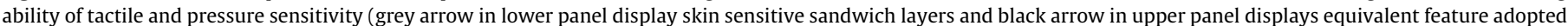
in synthetic smart fabrics).

Table 1

Commercial smart fabric products utilizing equivalent bioinspired approaches.

\begin{tabular}{|c|c|c|c|c|}
\hline $\begin{array}{l}\text { Smart fabric } \\
\text { description }\end{array}$ & Bioinspired property & Mechanistic approach & Product & Reference \\
\hline $\begin{array}{l}\text { Water repellence, } \\
\text { self-cleaning }\end{array}$ & $\begin{array}{l}\text { Water repellent via lotus } \\
\text { effect }\end{array}$ & Nano-whiskers as anti $\mathrm{H}_{2} \mathrm{O}$ repellent surface & $\begin{array}{l}\text { Schoeller }{ }^{\circledR}-W B-\text { formula, } \\
\text { canyon@Nanotex swela }{ }^{\circledR} \text { sunsilk SNC }\end{array}$ & {$[60,61]$} \\
\hline UV-protection & $\begin{array}{l}\text { Algae eyespot like UV- } \\
\text { sensitive, blocking units }\end{array}$ & $\begin{array}{l}\text { Semiconductor } \mathrm{TiO}_{2}, \mathrm{ZnO}, \mathrm{SiO} 2 \text { impregnated acrylic } \\
\text { sheet }\end{array}$ & ${ }^{\mathrm{a}}$ SunArt ${ }^{\mathrm{TM}}$ & {$[62,63]$} \\
\hline $\begin{array}{l}\text { Emotion and touch } \\
\text { sensitive fabric }\end{array}$ & $\begin{array}{l}\text { Mimosa plant inspired touch } \\
\text { sensitive features }\end{array}$ & $\begin{array}{l}\text { Soft technology by Philips utilizes integration of high } \\
\text { tech materials and electronic textile }\end{array}$ & SKIN $^{\mathrm{TM}}$ by Philips & {$[64]$} \\
\hline Breathing clothes & Pine cone derived features & $\begin{array}{l}\text { Equipped with heat panels, user controls and power } \\
\text { options }\end{array}$ & HEATwear $^{\mathrm{TM}}$ & {$[65]$} \\
\hline Camouflage cloth & $\begin{array}{l}\text { Chameleon skin inspired } \\
\text { features }\end{array}$ & $\begin{array}{l}\text { Concealing color patterns designed with selective dye } \\
\text { and weaving techniques }\end{array}$ & ULTRA FORCE ${ }^{\mathrm{TM}}$ & {$[66]$} \\
\hline Self healing features & Self-healing skin module & $\begin{array}{l}\text { Clear, glass-like plastic that can be broken and joined } \\
\text { Diels-Alder reversible reaction }\end{array}$ & ${ }^{\mathrm{a}}$ Automend ${ }^{\mathrm{TM}}$ & [67] \\
\hline Luminescent fabrics & Firefly glow module & $\begin{array}{l}\text { Wearable lighting systems using high brightness LED } \\
\text { lamp technology }\end{array}$ & i-Lume ${ }^{\mathrm{TM}}$, Fibretronic technology & [68] \\
\hline $\begin{array}{l}\text { Anti-tear or wrinkle } \\
\text { resistance }\end{array}$ & Spider silk inspired features & $\begin{array}{l}\text { Metal composite with impregnated nano-tex; } \\
\text { nano-silica with maleic anhydride (catalyst) }\end{array}$ & Everest@Nanotex & {$[69,70]$} \\
\hline $\begin{array}{l}\text { Antibacterial and } \\
\text { anti-drag } \\
\text { swimsuit }\end{array}$ & Shark skin inspired features & $\begin{array}{l}\text { Nanocrystalline } \mathrm{Al}_{2} \mathrm{O}_{3} \\
\mathrm{ZnO}, \mathrm{TiO}_{2} \text {, nanosilver }\end{array}$ & Fastskin $^{\mathrm{TM}}$, Acticoat $^{\mathrm{TM}}$, Sharklet ${ }^{\mathrm{TM}}$ & [71-73] \\
\hline $\begin{array}{l}\text { Thermo-mechanical } \\
\text { sensing }\end{array}$ & Skin like sensor & $\begin{array}{l}\text { User friendly performance status monitoring (PSM) } \\
\text { enabled software platform with sensor }\end{array}$ & OmniSense $^{\mathrm{TM}}$ BioHarness $^{\mathrm{TM}}$ & [74] \\
\hline
\end{tabular}

a Non-fabric products mimicking bioinspired approaches but product features have potential and amenability to be integrated with fabric technology. 
(sensitivity to pain and pressure) which are basically nerve endings, distributed in dermal layer of the skin (Fig. 10). The tactile perception of fine textures (spatial scale $<200 \mu \mathrm{m}$ ) conveyed by the populations of mechanosensitive afferent fibers is mediated by the texture characteristics of the skin sensors [56]. This is of the fundamental importance to understand the spacio-geometrical features and distribution of the skin sensor to design an analogous artificial stimuli responsive smart fabric.

In past several decades, technological developments in microelectromechanical systems (MEMS) and nanoelectromechanical systems (NEMS) have given us technological inputs to design smart sensors which can be designed and coupled with fabrics in array format [57]. In a simulation and experimental validation format, Tata et al. have shown the patch antenna printed on a flexible semiconducting substrate which acts as engineered sensor skins, which imitate the sense of pain via strain measurement of surrounding (Fig. 10). This could be a smart wearable device for future fabric for direct health monitoring and data mining-transmission for personalized medical care [58].

In another exciting development, Carlson et al. have designed an analogous skin like sensor exhibiting flexibility, self-healing and damage sensing functionalities. Using microfabrication techniques, a substrate of copper-clad polyimide sheets arranged in a layer-by-layer format, using polyimide sheets and an ultraviolet (UV)-curable epoxy has been used as both, a structural adhesive and as the self-healing fill material. These assemblies were coupled with arrayed LC circuits where each circuit was provided with unique resonance frequency. When damage occurs, the localized LC circuits senses the damage site via alteration in resonance frequency and subsequent release of UV-curable epoxy fills the damage site under ambient sunlight [59]. This artificial sensing and healing concept provides an exciting opportunity of wearable fabrics where accidental damage will automatically cover the underlying body parts. This may deliver therapeutics too if UV-curable epoxy could be replaced with a self healing polymer loaded with drug.

\section{Conclusions}

Nature has its own plans to design complex yet efficient structures which perform diverse functions in animal and plants. Mimicking such structures based upon current advances in scientific technologies and tolls to integrate them in fabrics provide challenges and opportunities to design smart interactive clothing. Some of these ideas inspired by nature have gained their place into smart apparel design, yet few waiting to find the way to be mimicked and integrated into fabrics due the hierarchical complexity as fundamental hurdle. However, technical and technological boost provides an alternative strategy to mimic functional aspect rather than structural as we mentioned in few examples reviewed herewith (firefly glow, self healing fabric). At present, the subject of biomimesis and bioinspired designs for smart clothing is at the frontier between advance material design and their subsequent integration into fabrics. In future, accurate mimicry of bioinspired complex designs would require greater understanding of principles and perceptions, to incorporate it into textile designs. However, we predict that as scientific advances continue to unfold and uncover finer details, bioinspired emulations may increasingly give way to benefit in designing smart fabrics. It represents a major international competitive sector of research for the coming years to realize "smart fabrics" with interactive features. A large number of commercially viable smart fabric products are in textile markets which largely involve bioinspired approaches and/or plausibility to integrate with current fabric technology to build interactive apparel (Table 1).

\section{Conflict of interest}

The authors state no conflict of interest.

\section{Acknowledgements}

AVS thanks to European School of Molecular Medicine (SEMM) for supporting his research grant in medical nanotechnology. We gratefully acknowledge Prof. Jonathon Web for critically revising the manuscript for spell check and grammatical errors.

\section{References}

[1] Bar-Cohen Y. Biomimetics - using nature to inspire human innovation. Bioinspir Biomim 2006;1:1-12.

[2] Krausse E. In: Engels E-M, editor. Die Rezeption von Evolutionstheorien im Jahrhundert, Nineteenth ed., Frankfurt; 1995.

[3] Thompson DW. On growth and form. Cambridge Univ. Press; 1942.

[4] Ball P. Life's lessons in design. Nature 2001;409(6818):413-6.

[5] Ahmed D. Hybridization of smart textiles in medical in medical and healthcare management. AUTEX 2009 world textile conference, İzmir, Turkey 26-28 May, 2009.

[6] Sarikaya M. Biomimetics: materials fabrication through biology. Proc Natl Acad Sci USA 1999;96(25):14183-5.

[7] Carlson J, Ghaey S, Moran S, Tran CA, Kaplan DL. Biological materials in engineering mechanisms. In: Biomimetics-biologically inspired technologies. Boca Raton (FL): CRC Press; 2005. p. 365-80 [chapter 14]

[8] Fratzl P, Barth FG. Biomaterial systems for mechanosensing and actuation. Nature 2009;462(7272):442-8

[9] Sanchez C, Arribart H, Guille MM. Biomimetism and bioinspiration as tools for the design of innovative materials and systems. Nat Mater 2005;4(4):277-88.

[10] Humphrey JAC, Barth FG, Reed M, Spak A. In: Barth FG, Humphrey JAC, Secomb TW, editors. Sensors \& sensing in biology \& engineering. Springer; 2003. p. 129-44.

[11] Bar-Cohen Y. In: Biomimetics: biologically inspired technologies. Boca Raton (FL): CRC Press; 2006. p. 2-40.

[12] Biggins PD, Kusterbeck A, Hiltz JA. Bio-inspired approaches to sensing for defence and security applications. Analyst 2008;133(5):563-70.

[13] Bhushan B, Jung YC, Koch K. Micro-, nano- and hierarchical structures for superhydrophobicity, self-cleaning and low adhesion. Philos Trans A Math Phys Eng Sci 2009;367(1894):1631-72.

[14] Parness A, Soto D, Esparza N, Gravish N, Wilkinson M, Autumn K, et al. A microfabricated wedge-shaped adhesive array displaying gecko-like dynamic adhesion, directionality and long lifetime. J R Soc Interface 2009;6(41):1223-32.

[15] Meoli D, May-Plumlee T. Interactive electronic textile development: a review of technologies. JTATM 2002;2(2):1-12.

[16] Guo Z, Liu W. Biomimic from the superhydrophobic plant leaves in nature: binary structure and unitary structure. Plant Sci 2007;172:1103-12.

[17] Bae GY, Jang J, Jeong YG, Lyoo WS, Min BG. Superhydrophobic PLA fabrics prepared by UV photo-grafting of hydrophobic silica particles possessing vinyl groups. J Colloid Interf Sci 2010;344(2):584-7.

[18] Selbach M, Kuhlmann HW. Structure, fluorescent properties and proposed function in phototaxis of the stigma apparatus in the ciliate chlamydodon Mnemosyne. J Exp Biol 1999;202:919-27.

[19] Yu J, Tao X, Tam H. Trans-4-stilbenemethanol-doped photosensitive polymer fibers and gratings. Opt Lett 2004;29(2):156-8.

[20] Watanabe S, Sibaoka T. Site of photo-reception to opening response in Mimosa leaflets. Plant Cell Physiol 1973;14:1221-4.

[21] Abe T. The shortening and action potential of the Cortex in the main pulvinus of Mimosa pudica. Bot Mag (Tokyo) 1980;93:247-51.

[22] Bonnani L, Lieberman J, Vaucelle C, Zuckerman O. TapTap: a haptic wearable for asynchronous distributed touch therapy. In: CHI '06; 2006.

[23] Bickmore T, Fernando R. Towards empathic touch by relational agents. In: Decker, Sichman, Sierra, Castelfranchi, editors. Proc of 8th int conf autonomous agent and multiagent systems (AAMAS 2009), May, 10-15, 2009, Budapest, Hungary. p. 1-4.

[24] Heitz E. Das Heterochromatin der Moose. Jb Wiss Bot 1928;69:762-818.

[25] Dawson C, Vincent JFV, Rocca AM. How pine cones open. Nature 1997;390:668.

[26] Elbaum R, Gorb S, Fratzl P. Structures in the cell wall that enable hygroscopic movement of wheat awns. J Struct Biol 2008;164:101-7.

[27] <http://news.nationalgeographic.com/news/2004/10/ 1013_041013_smart_clothing_2.html> [accessed 22.07.10].

[28] Stuart-Fox D, Moussalli A. Camouflage, communication and thermoregulation: lessons from colour changing organisms. Philos Trans Roy Soc Lond B Biol Sci 2009;364:463-70.

[29] Pennycuick CJ. Newton rules biology: a physical approach to biological problems. Oxford Univ. Press; 1992. p. 30-39.

[30] Source: Camouflage; Harris, Tom. How animal camouflage works. how stuff works. <http://science.howstuffworks.com/animal-camouflage2.htm> [retrieved 03.05.10]. 
[31] Thermal and visual camouflage system patent no. 6338292, United States Patent \& Trademark Office.

[32] Wowk B. Phased array optics. In: Crandall BC, editor. Molecular speculations on global abundance. MIT Press; 1996. p. 147-60.

[33] Trask RS, Williams HR, Bond IP. Self-healing polymer composites: mimicking nature to enhance performance. Bioinspir Biomim 2007;2:1-9.

[34] Macfarlane RG. An enzyme cascade in the blood clotting mechanism, and its function as a biochemical amplifier. Nature 1964;202:498-9.

[35] Williams HR, Trask RS, Bond IP. Vascular self-healing composite sandwich structures 15th United States national congress of theoretical and applied mechanics, Boulder, CO, 25-31 June; 2006.

[36] White SR, Sottos NR, Geubelle PH, Moore JS, Kessler MR, Sriram SR, et al. Autonomic healing of polymer composites. Nature 2001;409:794.

[37] Kessler MR, Sottos NR, White SR. Self-healing structural composite materials. Composites A 2003;34:743-53.

[38] Cordier P, Tournilhac F, Soulié-Ziakovic C, Leibler L. Self-healing and thermo reversible rubber from supramolecular assembly. Nature 2008;451:977-80.

[39] Tong D, Rozas NS, Oakley TH, Mitchell J, Colley NJ, McFall-Ngai MJ. Evidence for light perception in a bioluminescent organ. Proc Natl Acad Sci USA 2009;106:9836-41.

[40] Buechley L, Eisenberg M. Fabric PCBs, electronic sequins, and socket buttons: techniques for e-textile craft. Pers Ubi Comput 2009;13:133-50.

[41] Wainwright, Harry L. (918 Delaware Ave., Bethlehem, PA, 18015) [1989 \#sqFabric with illuminated changing display United States; patent no. 4875144. <http://www.freepatentsonline.com/4875144.html>.

[42] Source: <http://www.lumalive.com/Products> [accessed 7.05.10]

[43] Barth FG, Bleckmann H, Bohnenberger J, Seyfarth EA. Spiders of the genus Cupiennius Simon 1891 (Araneae, Ctenidae). Oecologia 1988;77:194-201.

[44] Neville AC. Biology of the arthropod cuticle. NY: Springer; 1975.

[45] Vollrath F, Knight DP. Liquid crystalline spinning of spider silk. Nature 2001;410:541-8.

[46] Termonia Y. Molecular modeling of spider silk elasticity. Macromolecules 1994;27:7378-81.

[47] Liff SM, Kumar N, McKinley GH. High-performance elastomeric nanocomposites via solvent-exchange processing. Nat Mater 2007;6:76-83.

[48] Bechert DW, Bruse M, Hage W, van der Hoeven JGT, Hoppe G. Experiments on drag-reducing surfaces and their optimization with an adjustable geometry. J Fluid Mech 1997;338:59-87.

[49] Martin RA. The Importance of Being Cartilaginous. ReefQuest Centre for Shark Research. <http://www.elasmo-research.org/education/topics/p_cartilage.htm> [retrieved 05.05.10].

[50] Source: <http://www.popsci.com/science/article/2009-10/saving-skin>

[51] Flight-test of turbulent skin-friction reduction by riblets. In: Douglas MJ, Falvy G, Dezson S, Peter P, editors. Turbulent drag reduction by passive means; proceedings of the international conference, vols. 15-17, London, England, United Kingdom; 1987. p. 408-24
[52] Source:

<http://news.discovery.com/tech/top-5-shark-tech-04.html> [accessed 5.05.10].

[53] Schumacher JF, Carman ML, Estes TG, Feinberg AW, Wilson LH, Callow ME, et al. Engineered antifouling microtopographies - effect of feature size, geometry, and roughness on settlement of zoospores of the green alga. Biofouling 2007;23:55-62.

[54] David MZ, Siegel JD, Chambers HF, Daum RS. Determining whether methicillin-resistant Staphylococcus aureus is associated with health care. JAMA 2008;299:519-20.

[55] Proksch E, Brandner JM, Jensen JM. The skin: an indispensable barrier. Exp Dermatol 2008;17:1063-72.

[56] Scheibert J, Leurent S, Prevost A, Debrégeas G. The role of fingerprints in the coding of tactile information probed with a biomimetic sensor. Science 2009;323:1503-6.

[57] Lumelsky VJ, Shur MS, Wganer S. Sensitive skin. IEEE Sens J 2001;1:41-51.

[58] Uday T, Deshmukh S, Chiao JC, Ronald C, Huang H. Bio-inspired sensor skins for structural health monitoring. Smart Mater Struct 2009;18: 104026-33.

[59] Carlson JA, English JM, Coe DJ. A flexible, self-healing sensor skin. Smart Mater Struct 2006;15:129-35.

[60] Zhang J, France P, Radomyselskiy A, Datta S, Zhao J, Ooij WV. Hydrophobic cotton fabric coated by a thin nanoparticulate plasma film. J Appl Polym Sci 2003;88:1473-81.

[61] <http://www.duckworthoutdoorsolutions.com/awning-fabric.html> [accessed 4.07.10].

[62] Wang RH, Xin JH, Yang Y, Liu HF, Xu LM, Hu JH. The characteristics and photocatalytic activities of silver doped ZnO nanocrystallites. Appl Surf Sci 2004;227:312-7.

[63] Yang HY, Zhu SK, Pan N. Studying the mechanisms of titanium dioxide as ultraviolet-blocking additive for films and fabrics by an improved scheme. J Appl Polym Sci 2003;92:3201-10.

[64] <http://www.design.philips.com/probes/projects/dresses/index.page> [accessed 12.08.10].

[65] <http://fibretronic.com/products/heatwear> [accessed 15.07.10]

[66] <http://www.camoclothingonline.com/site/1603000/product/883-8675> accessed 28.07.10].

[67] <http://automend.net/> [accessed 03.08.10].

[68] <http://fibretronic.com/products/ilume> [accessed 5.08.10].

[69] Wong YWH, Yuen CWM, Leung MYS, Ku SKA, Lam HLI. Selected applications of nanotechnology in textiles. AUTEX Res J 2006;6:191-8.

[70] <http://www.nano-tex.com/fabrics/resists_static.html> [accessed 15.08.10].

[71] Lee HJ, Yeo SY, Jeong SH. Antibacterial effect of nanosized silver colloidal solution on textile fabrics. J Mater Sci 2003;38:2199-204.

[72] <http://www.sharklet.com/> [accessed 17.08.10].

[73] <http://www.masternuoto.it/> [accessed 09.08.10].

[74] <http://www.zephyr-technology.com/products.html> [accessed 22.07.10] 